\title{
Evaluation of preventable causes and risk factors of maternal mortality
}

\section{Ruby Bhatia, Manjit Kaur Mohi*, Neeraj Singh}

Department of Obstetrics and Gynecology, Government Medical College, Patiala, Punjab, India

Received: 19 May 2018

Accepted: 10 August 2018

\section{*Correspondence:}

Dr. Manjit Kaur Mohi,

E-mail: manjitmohi@yahoo.co.in

Copyright: (c) the author(s), publisher and licensee Medip Academy. This is an open-access article distributed under the terms of the Creative Commons Attribution Non-Commercial License, which permits unrestricted non-commercial use, distribution, and reproduction in any medium, provided the original work is properly cited.

\section{ABSTRACT}

Background: The primary objective was to evaluate preventable causes of maternal deaths at tertiary, second and primary care in Patiala district, Punjab. Secondary objective was to determine impact of socio-demographic characteristics, anemia and three delays on maternal death.

Methods: This is a retrospective observational study carried out between 1. 7. 2013 till 30. 6. 2014, for period of one year in department of a tertiary care hospital and district health authorities catering to secondary and primary care deaths for evaluation of preventable causes and risk factors for maternal deaths at tertiary, secondary and primary level.

Results: A total of 54 maternal deaths with MMR of 170.42/100000 live births, occurred in stipulated period, $87.03 \%$ at tertiary care, one at second care, $7.41 \%$ at home and $3.7 \%$ on the way to tertiary care. Majority of maternal deaths $(92.6 \%)$ were unbooked, between $21-30$ years $(64.82 \%)$ of age, primi or second gravida $(35.18 \%)$, para 1 or 2 $(37.03 \%)$, illiterate $(40.74 \%)$, low income group $(57.41 \%)$ with rural background $(59.26 \%)$. Majority of maternal deaths $(77.7 \%)$ occurred in postpartum period. Most of maternal deaths (75.93\%) were due to direct causes, preeclampsia $25.93 \%$ followed by sepsis $(22.2 \%)$ and haemorrhage $(20.3 \%)$. Anemia was contributory factor in $79.63 \%$ maternal deaths. $7.4 \%$ maternal deaths occurred at home with delay in seeking care while $29.62 \%$ died due to delay in reaching care. In $40.42 \%$ maternal deaths, it took more than two hours to reach tertiary care hospital.

Conclusions: Skilled antenatal, intranatal and postnatal care, women empowerment, counseling, early diagnosis and referral of pre-eclampsia and other high-risk cases with curbing anemia at grass root level is need of millennium. Preventing delay in seeking care or reaching care-a step towards sustainable development goals (SDG) to reduce MMR.

Keywords: Anemia, Haemorrhage, Maternal mortality, Preeclampsia, Sepsis

\section{INTRODUCTION}

On an average 830 women die everyday due to avoidable pregnancy and childbirth related causes across the globe while 120 of these women die everyday in India alone. ${ }^{1,2}$ WHO defines maternal death as death of a woman when pregnant or within 42 day of termination of pregnancy from any cause related to or aggravated by pregnancy or its management but not from accidental or incidental causes. ${ }^{3}$ The maternal mortality ratio (MMR) expressed as maternal deaths per 100,000 live birth over a period of time is an important measure of quality of obstetric care and maternal health. ${ }^{4}$ MMR is $239 / 100,000$ live births in developing countries as compared to 12 per 100,000 live births in developed world. ${ }^{1} 99 \%$ of all maternal deaths are still occurring in the developing world being higher in women living in rural areas and among poor communities. Though millennium development goal-5 (MGD-5) to achieve MMR of 109, could not be achieved by India till 2015, there has been steady decline in MMR from 398 in 1997-98, 301 in 2001-03 to 212 per 100,000 livebirths in 2007-09 and 167 in 2011-12 and likely to 
decline to 140 by $2015 .^{2}$ Patiala with a population of 1895686 is a prosperous district of Punjab, a high empowered state of north India with a population of 2.77 crore. MMR in Punjab has declined from 172 (2007-09) to 141 per 100,000 live births by 2015 , however aim was to reach MMR of 95 by 2015 and further 78 per 100,000 live births by $2017 .{ }^{5}$ Global strategy for women, children and adolescents health towards Ending Preventable Maternal Mortality (EPMM) has set up Sustainable Development Goals (SDGs)-a transition from MDGs with an average global MMR of $<70 / 100,000$ live births by $2030 .^{6}$ Critically analyzing preventable causes and associated risk factors i.e. age, parity, socio-economic status, education, area of residence, leading to maternal death is need of hour with a focus on whether maternal death is in antenatal, intranatal or postnatal period. Anemia as indirect cause still contributes to majority of maternal deaths in India. To reduce MMR further it is highly essential to stress whether the delays occurred in seeking care, reaching care or receiving care. Any of the three delays can till the balance between life or maternal death. $^{7}$

\section{METHODS}

It was a retrospective observational study carried out between $1^{\text {st }}$ July 2013 till $30^{\text {th }}$ June 2014 for a period of one year in department of Obstetrics and Gynaecology, in Government Medical College and Rajindra Hospital, Patiala and Patiala district health authorities.

\section{Inclusion criteria}

- All consecutive maternal deaths in antenatal, intranatal or postnatal period within 42 days of delivery, or, direct or indirect causes of termination of pregnancy/ pregnancy related complications, in the given period were included in the study.

- All above mentioned maternal deaths at home, primary, secondary or tertiary care, during stipulated time period, were included and critically analysed.

\section{Exclusion criteria}

- Maternal deaths due to accidental causes or poisoning were excluded from the study.

Impact of socio-demographic characteristics and degree of anaemia on maternal death were analyzed. Any delays in seeking care, reaching care or receiving care was also noted. Period of death whether antenatal, intranatal or postnatal was also recorded.

\section{RESULTS}

A total of 54 maternal deaths occurred in Patiala district w.e.f. 1.7.2013 to 30.6 .2014 with 33,927 deliveries and 31,687 live births. MMR of Patiala district was 170.42/100,000 live births. Only 21 (38.9\%) maternal deaths occurred for Patiala residents while majority 33
(61.1\%) maternal deaths were among patients referred from adjoining districts of Punjab or Haryana State (Table1).

Table 1: MMR of Patiala district, Punjab.

\begin{tabular}{|lll|}
\hline $\begin{array}{l}\text { Maternal deaths among } \\
\text { residents of Patiala district }\end{array}$ & 21 & 38.9 \\
\hline $\begin{array}{l}\text { Maternal death among refer in } \\
\text { (adjoining district + Haryana) }\end{array}$ & 33 & 61.1 \\
\hline Total maternal deaths & 54 & 100 \\
\hline Total deliveries & 33927 & - \\
\hline Total live births & 31687 & - \\
\hline & $170.42 /$ \\
\hline MMR of Patiala & $\begin{array}{l}100,000 \\
\text { live births }\end{array}$ \\
\hline
\end{tabular}

A total of $47(87.03 \%)$ maternal deaths occurred at tertiary care hospitals, 44(81.45\%) in Emergency labour room/ICU Department of Obstetrics and Gynaecology, GMC, Rajindra Hospital, Patiala catering to whole of Punjab and parts of Haryana state. 3.7\% (two) maternal deaths occurred in government T.B. hospital while one maternal death $(1.85 \%)$ was reported from private sector tertiary care Columbia Asia hospital. 1.85\% (one mother died at second care Civil Hospital, Nabha). 7.41\% (four) maternal deaths occurred at home without any primary care. Two maternal deaths $(3.70 \%)$ occurred on the way to tertiary care hospital, Rajindra Hospital (Table 2).

Table 2: Distribution of maternal deaths according to level of care.

\begin{tabular}{|l|l|l|}
\hline Place of maternal death & No. & Percentage \\
\hline Tertiary care hospital & 47 & 87.03 \\
\hline GMC/ Rajindra hospital & 44 & 81.48 \\
\hline Govt. T.B. hospital & 2 & 3.70 \\
\hline Private Columbia Asia hospital & 1 & 1.85 \\
\hline Death at civil hospital (second care) & 1 & 1.85 \\
\hline Death at home (before primary care) & 4 & 7.41 \\
\hline Death on the way to tertiary care & 2 & 3.70 \\
\hline Total & 54 & 100 \\
\hline
\end{tabular}

Majority (92.6\%) of maternal deaths were unbooked pregnancy with occasional checkups while only $7.4 \%$ were booked. Majority 35 (64.82\%) of maternal deaths occurred in peak reproductive age group of 21-30 years. While $12.96 \%$ (seven) maternal deaths were in women $<20$ years of age. Two maternal deaths $(3.70 \%)$ each were in 36-40 years age group and $>41$ years respectively. $51.85 \%$ (28) dying pregnant women came in antenatal period while 26(48.14\%) were admitted in postnatal period. Among antenatal, $14.81 \%$ (eight) were primigravida, eleven $(20.37 \%)$ second gravida and $14.81 \%$ (eight) were gravida-4. Among $48.14 \%$ postnatal admissions, $27.77 \%$ (Fifteen) were para one, $9.26 \%$ (five) para-2 and $7.40 \%$ (four) were para-3. Only two women (3.70\%) were para-5. Majority 59.26\% (32) of maternal deaths occurred in rural residents while $40.74 \%$ (22) 
dying women were from urban area. $40.74 \%$ (22) were illiterate, $25.92 \%$ (14) were educated up to $\leq$ class VIII. $14.81 \%$ (eight) studied $\leq$ class XII. Only $7.4 \%$ (four) deaths were in women educated up to graduation. Majority of $57.41 \%$ (31) maternal deaths occurred in women from lower socio-economic status while $22.22 \%$ (12) cases were from lower middle class and only $20.37 \%$ (11 cases) from upper middle class (Table 3 ).

Table 3: Socio-demographic characteristics in relation to maternal deaths.

\begin{tabular}{|c|c|c|}
\hline & No. & Percentage \\
\hline Booked & 4 & 7.4 \\
\hline Unbooked/ occasional checkup & 50 & 92.6 \\
\hline \multicolumn{3}{|l|}{ Age in years } \\
\hline$<20$ & 7 & 12.96 \\
\hline $21-25$ & 21 & 38.89 \\
\hline $26-30$ & 14 & 25.93 \\
\hline $31-35$ & 8 & 14.81 \\
\hline $36-40$ & 2 & 3.70 \\
\hline$\geq 41$ & 2 & 3.70 \\
\hline \multicolumn{3}{|l|}{$\overline{\text { Gravidity/ parity at admission }}$} \\
\hline Antenatal admission & 28 & 51.85 \\
\hline Primigravida & 8 & 14.81 \\
\hline G2 & 11 & 20.37 \\
\hline G3 & 1 & 1.85 \\
\hline G4 & 8 & 14.85 \\
\hline Postnatal admission & 26 & 48.14 \\
\hline Para-1 & 15 & 27.77 \\
\hline Para-2 & 5 & 9.26 \\
\hline Para-3 & 4 & 7.40 \\
\hline Para-4 & - & - \\
\hline Para-5 & 2 & 3.70 \\
\hline \multicolumn{3}{|l|}{ Residence } \\
\hline Rural & 32 & 59.26 \\
\hline Urban & 22 & 40.74 \\
\hline \multicolumn{3}{|l|}{ Education } \\
\hline Illiterate & 22 & 40.74 \\
\hline$\leq$ Class VIII & 14 & 25.92 \\
\hline$\leq$ Class X & 6 & 11.11 \\
\hline$\leq$ Class XII & 8 & 14.81 \\
\hline$\leq \mathrm{Up}$ to B.A. & 4 & 7.40 \\
\hline \multicolumn{3}{|l|}{ Socio-economic status } \\
\hline Lower & 31 & 57.41 \\
\hline Lower middle & 12 & 22.22 \\
\hline Upper middle & 11 & 20.37 \\
\hline High & - & - \\
\hline
\end{tabular}

Table 4: Maternal deaths in relation to period of pregnancy.

\begin{tabular}{|ll|l|}
\hline $\begin{array}{l}\text { Period of pregnancy } \\
\text { at time of death }\end{array}$ & No. & Percentage \\
\hline Antenatal & 11 & 20.37 \\
\hline Intranatal & 1 & 1.85 \\
\hline Postnatal & 42 & 77.77 \\
\hline Total & 54 & 100 \\
\hline
\end{tabular}

$77.77 \%$ (42) maternal deaths were in postnatal period, while $11(20.37 \%)$ were in antenatal period and only one $(1.85 \%)$ maternal death occurred during delivery (Table 4).

Table 5: Causes of maternal death.

\begin{tabular}{|lll|}
\hline Causes & No. & Percentage \\
\hline Direct causes & 43 & 75.93 \\
\hline Haemorrhage & 11 & 20.37 \\
\hline APH & 4 & 7.41 \\
\hline PPH & 7 & 12.96 \\
\hline Sepsis & 12 & 22.22 \\
\hline Severe preeclampsia and eclampsia & 14 & 25.93 \\
\hline Pulmonary emobolism & 2 & 3.70 \\
\hline Obstructed labour with rupture uterus & 2 & 3.70 \\
\hline Indirect causes & 13 & 24.07 \\
\hline Anemia & 43 & 79.63 \\
\hline Cardiac disease in pregnancy & 5 & 9.26 \\
\hline Jaundice in pregnancy & 5 & 9.26 \\
\hline Pulmonary tuberculosis & 2 & 3.70 \\
\hline Epilepsy & 1 & 1.85 \\
\hline
\end{tabular}

Majority of maternal deaths $75.93 \%(n=43)$ were due to direct causes. Severe preeclampsia and eclampsia were most important direct cause, leading to 14 (25.93\%) maternal deaths. Sepsis was second important direct cause leading to $22.22 \%$ (12) maternal deaths. $20.37 \%$ (11) women died of haemorrhage of which four $(7.41 \%)$ were due to antepartum haemorrhage and seven (12.96 $\%$ ) were due to PPH. Pulmonary embolism and obstructed labour with rupture uterus were responsible for two deaths (3.70\%) each. $24.07 \%$ (13) maternal deaths were due to Indirect causes. Five deaths $(9.26 \%)$ each occurred due to cardiac disease and jaundice respectively. Two $(3.70 \%)$ maternal deaths occurred due to pulmonary tuberculosis and one $(1.85 \%)$ death due to epilepsy (Table 5).

Table 6: Anemia in relation to maternal deaths.

\begin{tabular}{|lll|}
\hline Anemia present & No. & Percentage \\
\hline Mild anemia $(\mathrm{Hb} 9$ to $<11 \mathrm{~g} / \mathrm{dl})$ & 33 & 79.63 \\
\hline Moderate anemia $(\mathrm{Hb} 7 \mathrm{to}<9 \mathrm{~g} / \mathrm{dl})$ & 27 & 50.55 \\
\hline Severe anemia $(\mathrm{Hb} 4$ to $<7 \mathrm{~g} / \mathrm{dl})$ & 5 & 9.26 \\
\hline Very severe anemia $(\mathrm{Hb}<4 \mathrm{~g} / \mathrm{dl})$ & 8 & 14.81 \\
\hline No anemia $(\mathrm{Hb} \geq 11 \mathrm{~g} / \mathrm{dl})$ & 11 & 20.37 \\
\hline Total & 54 & 100 \\
\hline
\end{tabular}

Anemia as indirect cause of maternal death was present in $79.63 \%$ (43) of maternal deaths. Moderate anemia was present in $50 \%$ (27) maternal deaths. $14.81 \%$ (8) maternal deaths had very severe anemia and $9.26 \%$ (five cases) had severe anemia (Table 6).

A total of 47 maternal deaths occurred at tertiary care hospitals. Only $8.51 \%$ (four) of these were booked at tertiary care. Out of total $47,91.48 \%$ (43) maternal deaths were referred patients. $24(51.06 \%)$ being referred with in 
travel distance of two hours, while 19 (40.42\%) cases referred from other hospitals had to travel a distance more than two hours to reach tertiary care from referring centre. Seven $(14.89 \%)$ maternal deaths were among patients referred from adjoining state Haryana while 20 $(42.54 \%)$ of dying women were referred from adjacent districts of Punjab. Only $16(34.07 \%)$ maternal deaths were from Patiala district itself (Table 7).

Table 7: Analysis of maternal deaths at tertiary care.

\begin{tabular}{|lll|}
\hline $\begin{array}{l}\text { Analysis in relation to } \\
\text { distance travelled }\end{array}$ & No. & Percentage \\
\hline $\begin{array}{l}\text { Total maternal deaths at tertiary } \\
\text { care }\end{array}$ & 47 & 100 \\
\hline $\begin{array}{l}\text { Booked at tertiary care } \\
\text { Maternal deaths in patients } \\
\text { referred from peripheral hospitals }\end{array}$ & 4 & 8.51 \\
\hline Within $\leq 2$ hours travel distance & 24 & 91.48 \\
\hline Patiala-Punjab & 16 & 31.06 \\
\hline Sangrur-Punjab & 5 & 10.64 \\
\hline Fatehgarh Sahib-Punjab & 3 & 6.38 \\
\hline$>2$ hours travel distance & 19 & 40.42 \\
\hline Ludhiana-Punjab & 6 & 12.76 \\
\hline Barnala-Punjab & 5 & 10.64 \\
\hline Mansa-Punjab & 1 & 2.12 \\
\hline Haryana & 7 & 14.89 \\
\hline
\end{tabular}

There was delay in seeking care in $7.4 \%$ (four) cases where maternal death occurred at home itself due to lack of awareness regarding health care facilities. There was delay in reaching tertiary care in a total of $16(29.62 \%)$ cases, as one case $(1.85 \%)$ died at secondary care level, two $(3.70 \%)$ cases died on the way to tertiary care level. While $24.07 \%$ (13) one quarter of maternal deaths occurred within six hours of reaching tertiary care (Table $8)$.

Table 8: Analysis of maternal deaths in relation to type of delay.

\begin{tabular}{|lll|}
\hline Type of delay & No. & \% age \\
\hline $\begin{array}{l}\text { Delay in seeking care } \\
\text { (Home deaths) }\end{array}$ & 4 & 7.24 \\
\hline $\begin{array}{l}\text { Delay in reaching tertiary } \\
\text { care }\end{array}$ & 16 & 29.62 \\
\hline Death at second care & 1 & 1.85 \\
\hline Death on way & 2 & 3.70 \\
\hline $\begin{array}{l}\text { Death within 6 hr. of } \\
\text { reaching tertiary care }\end{array}$ & 13 & 24.07 \\
\hline Delay in receiving care & - & - \\
\hline
\end{tabular}

\section{DISCUSSION}

MMR of Patiala district for year 2013-14 during study period was $170.42 / 100,000$ live births. MMR is 239/100,000 live births in developing countries. MMR of India and Punjab is 167 per 100,000 live births and 141 per 100,000 live births respectively. ${ }^{2,5}$ Present is a tertiary care centre catering to majority of Punjab district and adjoining state of Haryana, hence a little higher MMR. Majority of $(92.6 \%)$ maternal deaths occurred in unbooked pregnancies, during peak reproductive $(64.82 \%)$ age group of $21-30$ years, in illiterate $(40.74 \%)$ women with rural $(59.26 \%)$ background with low/ lowmiddle socioeconomic group (79.63\%). Bhasker K. Murthy et al. 2013 also observed similar results. ${ }^{8}$

Majority (75.93\%) maternal deaths were due to Direct causes while $24.07 \%$ deaths occurred due to indirect causes in present study. Kausar $\mathrm{R}$ also reported majority $(81 \%)$ of maternal deaths due to direct causes. ${ }^{9}$ Severe preeclampsia and eclampsia (25.93\%) followed by sepsis $(22.22 \%)$ and haemorrhage $(20.37 \%)$ were leading direct causes of maternal death in present study. Pre-eclampsia and eclampsia remain leading cause of mortality worldwide as other comorbidities like post-partum haemorrhage and infections are being managed in a better way. ${ }^{10}$ A FOGSI study also observed hypertension $(29.4 \%)$ as leading direct cause of maternal death followed by haemorrhage and sepsis. ${ }^{11} 75 \%$ of maternal deaths are due to direct causes mainly haemorrhage, infections, preeclampsia, complications from delivery and unsafe abortions. ${ }^{12}$ Paul B et al reported hemorrhage, sepsis, abortion, hypertensive disorders and obstructed labour as important direct causes of maternal mortality. ${ }^{13}$

Anemia was associated indirect cause in $79.63 \%$ of maternal deaths in present study. $50 \%$ of dying women had moderate anemia while $24.07 \%$ maternal deaths had severe or very severe anemia. Sarin A.R. also reported severe anemia in $34.5 \%$ of maternal deaths. ${ }^{14}$ Anemia remains the most common $(48.8 \%)$ contributory cause of maternal death. ${ }^{5} 77.77 \%$ maternal deaths occurred after childbirth in postnatal period while $20.37 \%$ in antenatal period and one death occurred during intrapartum period in present study. However, Barnet S observed quarter of maternal deaths in antenatal and postnatal and half in intrapartum period. ${ }^{15}$ Majority of maternal deaths $(91.4 \%$ occurred in patients referred from other hospitals. Only $16(34.04 \%)$ maternal deaths were from Patiala district while rest were referred in patients from adjoining district of Punjab and Haryana state. $24(51.06 \%)$ refer in maternal deaths at tertiary care had to travel up to two hours to reach tertiary care referral centre while in $40.42 \%$ (19) maternal deaths, it took more than two hours to reach tertiary care hospital in present study. Maternal death review by NRHM reported that majority, $60 \%$ critical women reached referral institute within ten hours. $^{5}$ Out of total 54 maternal deaths, 47 (87.03\%) occurred at tertiary care. Four $(7.41 \%)$ maternal deaths occurred at home without seeking care. Poverty, lack of information, inadequate services and distance from health care facility prevent women from seeking care. ${ }^{12}$ Onewoman $(1.85 \%)$ died at secondary care, two women $(3.70 \%)$ died on the way to tertiary care while 13 $(24.07 \%)$ women died within six hours of reaching tertiary care. Thus, a total of $16(29.62 \%)$ approximately one third maternal deaths occurred due to Delay in 
reaching care. Delay in seeking, reaching care and receiving care remain major causes of avoidable maternal death. Delays at different levels has a vital role in maternal death. ${ }^{5}$

\section{CONCLUSION}

MMR of Patiala district in present study was $170.42 / 100,000$ live births. Majority of maternal deaths still occur in unbooked, illiterate women from low socioeconomic strata with rural background. The bulk of maternal deaths are in postnatal period stressing need for not only antenatal check-ups but mandatory four postnatal visits on day 1,3,7 and six weeks postpartum for all mothers. Pre-eclampsia and eclampsia are now leading direct cause of maternal death followed by sepsis and haemorrhage. Anemia as indirect cause is present in majority of maternal deaths with severe and very severe anaemia in quarter of maternal deaths. Deworming all mothers at 16 weeks and strict compliance for oral iron to be emphasized. Strengthening at primary care grass root level by trainings and orientation- workshops for medical officers and skilled birth attendants with timely and prompt referral can prevent many an avoidable maternal death. Counselling of couples at each antenatal visit regarding life threatening maternal complications shall be a step in preventing delay in seeking care. Mandatory public private partnership for maternal near miss refer in within two hours travel distance shall be a cornerstone in preventing any delay in reaching care. Women empowerment, skilled antenatal/ intranatal, postnatal care, curbing anemia, early detection of preeclampsia, couple counselling with no delay in seeking or reaching care and prompt referral shall go long way to prevent avoidable maternal deaths and help us to achieve sustainable development goal (SDGs) MMR <70/100,000 live births much before 2030. Focus on high risk women and hard to reach community is need of millennium.

Funding: No funding sources Conflict of interest: None declared

Ethical approval: The study was approved by the Institutional Ethics Committee

\section{REFERENCES}

1. WHO Maternal mortality fact sheet no. 348 (2016). Available at: http://www.who.int/news-room/factsheets/detail/maternal-mortality.

2. Millennium Development Goals India Country Report 2015. Social Statistics Division, Ministry of Statistics and Programme Implementation, Government of India. Available at:

http://mospi.nic.in/sites/default/files/publication_reports /mdg_2july15_1.pdf.

3. WHO, UNICEF, UNFPA, World Bank Group and United Nations Population Division. Trends in Maternal
Mortality; 1990-2015. Available at: https://afro.who.int/sites/default/files/2017-05/trends-inmaternal-mortality-1990-to-2015.pdf.

4. Vital Statistics division. Ministry of Health and Family Welfare. Registrar General of India, Special Bulletin on Maternal Mortality in India, 2014. Available at: http://www.censusindia.gov.in/vital_statistics/SRS_Bull etins/MMR\%20Bulletin-2014-16.pdf.

5. National Rural Health Mission, Maternal Death Review-Mother and Child Health Action Plan 2014-17, Dept. of Health \& Family Welfare, Govt. of Punjab. Available at:

http://pbhealth.gov.in/MCH\%20ACTION\%20PLAN\%2 02014-\%2017\%20\%281\%29.pdf.

6. Maternal Mortality (EPMM) HRP, UNDP, UNFPA, UNICEF, WHO, World Bank, 2015. Available at: www.who.int/reproductive health/topics.

7. Bemoc Training Gudelines, 2009-10. Ministry of Health \& Family Welfare, Government of India. Available at:

http://nhsrcindia.org/sites/default/files/Operational $\% 20$ Guidelines\%20for\%20Maternal\%20\%20Newborn\%20 Health.pdf.

8. Murthy BK, Murthy MB, Prabhu PM. Maternal mortality in a tertiary care hospital: a 10-year review. Int J Prevent Med. 2013;4(1):105-9.

9. Kausar R. Maternal mortality in India-magnitude cause and concerns. Indian J Pract Doc. 2005;2(2).

10. Abalos E, Cuesta C, Carroli G, Qureshi Z, Widmer M, Vogel JP, et al. Pre-eclampsia, eclampsia and adverse maternal and perinatal outcomes: a secondary analysis of the World Health Organization Multicountry Survey on Maternal and Newborn Health. BJOG: Int J Obstet Gynaecol. 2014;121:14-24.

11. Konar H, Chakraborty AB. Maternal mortality: a FOGSI study (based on institutional data). J Obstet Gynaeco India. 2013;63(2):88-95.

12. Maternal Mortality Fact Sheet (updated November, 2016). Available at: http://www.who.int/newsroom/fact-sheets/detail/maternal-mortality.

13. Paul B, Mohapatra B, Kar K. Maternal deaths in a tertiary health care centre of Odisha: an in-depth study supplemented by verbal autopsy. Indian J Comm Med: Official Publication Indian Assoc Prevent Social Med. 2011;36(3):213-6.

14. Sarin AR. Severe anemia of pregnancy, recent experience. Int J Obstet Gynaecol. 1995;50:S45-9.

15. Barnett S, Nair N, Tripathy $P$, Borghi J, Rath S, Costello A. A prospective key informant surveillance system to measure maternal mortality-findings from indigenous populations in Jharkhand and Orissa, India. BMC Pregn Childbirth. 2008;8(1):6.

Cite this article as: Bhatia R, Mohi MK, Singh N. Evaluation of preventable causes and risk factors of maternal mortality. Int J Reprod Contracept Obstet Gynecol 2018;7:4209-13. 